Tewes Tralau · Alasdair M. Cook · Jürgen Ruff

\title{
An additional regulator, TsaQ, is involved with TsaR in regulation of transport during the degradation of $p$-toluenesulfonate in Comamonas testosteroni T-2
}

\begin{abstract}
The degradation of $p$-toluenesulfonate (TSA) by Comamonas testosteroni $\mathrm{T}-2$ is initiated by a transport system (TsaST) and enzymes (TsaMBCD) encoded on the $t s a$ transposon, Tntsa, on the TSA plasmid (pTSA). Tntsa comprises an insert of $15 \mathrm{~kb}$ between two IS1071 elements. The left-hand $6 \mathrm{~kb}$ and the right-hand $6 \mathrm{~kb}$ are nearly mirror images. The regulator of the $t s a M B C D_{1}$ genes (righthand side) is the centrally located LysR-type TsaR, which is encoded upstream of $t s a M B C D_{1}$ on the reverse strand. The other centrally located genes are $t s a S$ and $t s a T$, encoded downstream of $t s a R$ and on the same strand as both tsaR and $t s a M B C D_{2}$. The latter four genes are not expressed. Downstream of $t s a D_{1}\left(t s a D_{2}\right)$ is $t s a Q_{1}\left(t s a Q_{2}\right)$ and another open reading frame of unknown function. The tsa $Q$ genes have identical sequences. Sequence analysis indicated that TsaQ could be an IclR-type regulator, whose expression during degradation of TSA was proven by data from RT-PCR. Both copies of $t s a Q$ could be knocked-out by homologous recombination. Double mutants failed to grow with TSA but grew with $p$-toluenecarboxylate (TCA), which is also degraded via TsaMBCD. This showed TsaQ to be essential for the degradation of TSA but not TCA. We attributed this to regulation of the transport of TSA, especially to regulation of the expression of $t s a T$, which was expressed solely during growth with TSA. Seven independently isolated bacteria containing the $t s a$ operon were available. Those six which contained tsaT on Tntsa also contained $t s a Q$. The promoter region of $t s a T$ was found to be a target of the regulator TsaR. Band-shift data indicate that TsaR is required for the expression of $t s a T$, which suggests that $t s a R$ and $t s a Q_{1,2}$, together with $t s a M B C D_{1}$, belong to a common regulatory unit.
\end{abstract}

T. Tralau · A. M. Cook · J. Ruff (凶)

Fachbereich Biologie, Universität Konstanz,

78457 Konstanz, Germany

Tel.: +49-7531-882100, Fax: +49-7531-884429,

e-mail: juergen.ruff@uni-konstanz.de

Present address:

T. Tralau

School of Biological Sciences, University of Manchester,

1.800 Stopford Building, Oxford Road, Manchester, M13 9PT, UK
Keywords. Regulation · Degradation · Transport · Toluene sulfonate $\cdot$ IclR family $\cdot$ LysR family

\section{Introduction}

$p$-Toluenesulfonate (TSA) is a biodegradable xenobiotic compound which is used in formulating household detergents and in industrial settings, so it enters many sewage works (e.g. Riediker et al. 2000). Three catabolic pathways for TSA are recognized in bacteria (Cook et al. 1999), but only that for sidechain oxygenation, which seems to be ubiquitious and has been characterized in Comamonas testosteroni T-2, is understood in any detail (Fig. 1; Locher et al. 1989; Cook et al. 1999; Tralau et al. 2001, 2003).

The degradation of TSA and its analogue $p$-toluenecarboxylate (TCA) requires enzymes encoded in four regulatory units (R1-R4; Fig. 1), two of which are plasmid-encoded (R1 on pTSA, R3 on pT2L; Junker and Cook 1997; Tralau et al. 2001) and two are chromosomally encoded (R2, R4; Junker and Cook 1997; Providenti et al. 2001), while regulon R3 seems to involve an IclR-type regulator (Ruff, unpublished data). The known portion of regulatory unit R1 is encoded as part of the insert in transposon Tntsa (Tralau et al. 2001, 2003; Fig. 1). The initial enzymatic reactions in the degradation of TSA (Fig. 1, R1) are identical with those in the initial steps of degradation of TCA (Locher et al. 1991), but physiological data show that the transport systems for these two growth substrates are different (Locher et al. 1993). The degradative reactions (TsaMBCD) are encoded by $t s a M B C D_{1}$ (Fig. 1); and the nearly identical $t s a M B C D_{2}$ genes are silent, as shown by RT-PCR (Tralau et al. 2001) and Tn5 knock-out of $t s a M_{1}$, which was not complemented by $t s a M B C D_{2}$ (Mampel 2000). The transport of TSA involves tsaT and tsaS (Fig. 1; Mampel 2000), but the location of transport genes for TCA is unknown.

The expression of $t s a M B C D_{1}$ is under the control of the LysR-type regulator, TsaR, which binds to perhaps four different sites in the divergent promoter region between tsaR and $t s a M B C D_{1}$ (Tralau et al. 2003). Downstream of 


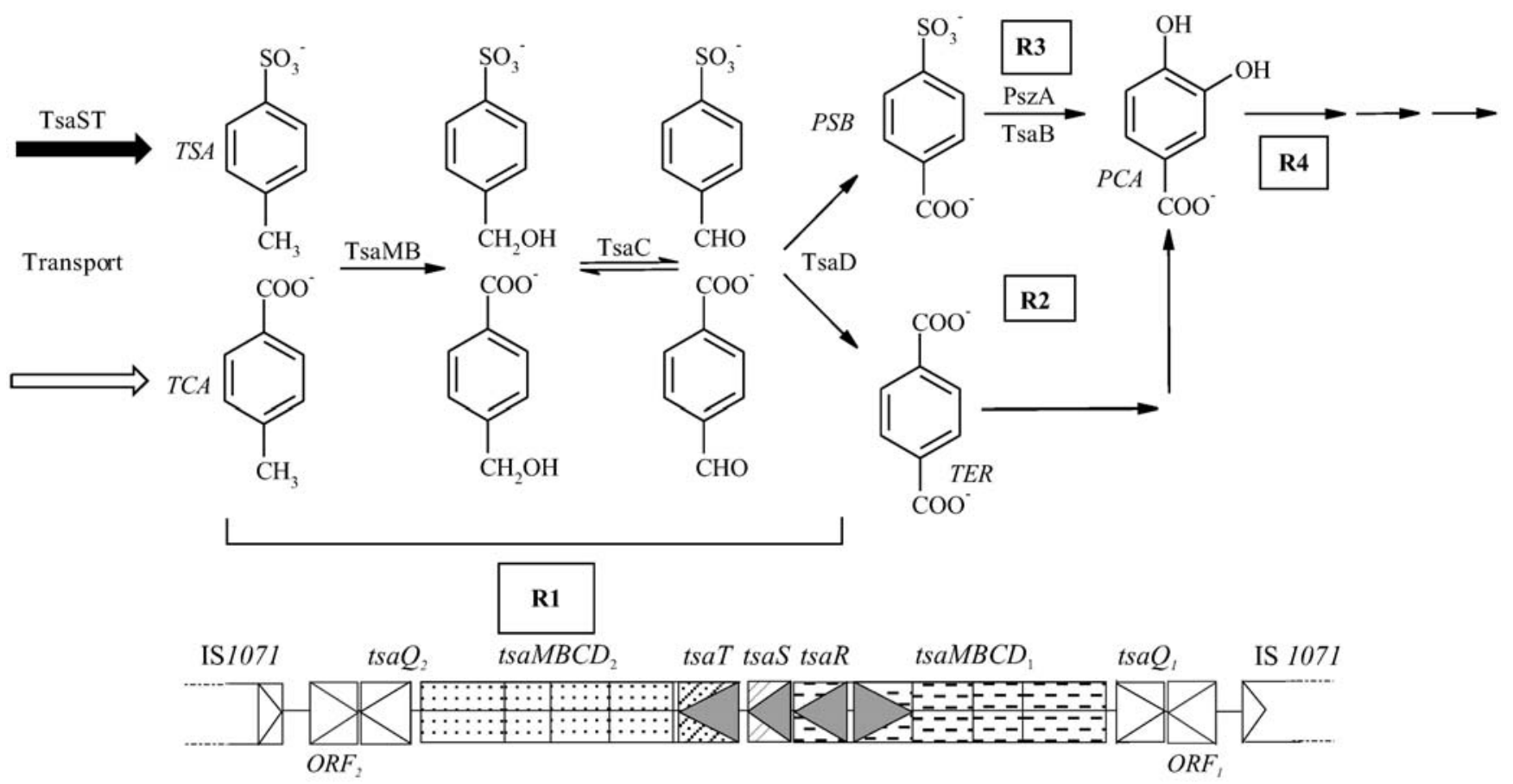

Fig. 1 The degradative pathway for $p$-toluenesulfonate (TSA) and $p$-toluenecarboxylate (TCA) in Comamonas testosteroni $\mathrm{T}-2$ and the structure of Tntsa on plasmid pTSA. The pathway is encoded in four regulons (R1-R4, see Introduction). Triangles indicate the direction of transcription of relevant genes in Tntsa (Tralau et al. 2001). PCA Protocatechuate, PSB p-sulfobenzoate, PszA p-sulfobenzoate-3,4-dioxygenase, TER terephthalate, TsaMB p-toluenesulfonate methylmonooxygenase, TsaC p-sulfobenzylalcohol dehydrogenase, TsaD p-sulfobenzaldehyde dehydrogenase, TsaR ( $t s a R)$ LysR type regulator, TsaST (TsaS, TsaT; tsaS, tsaT) components of transport of TSA (Mampel 2000), TsaQ IclR-type regulator, $O R F_{1}$ and $\mathrm{ORF}_{2}$ encode similar putative proteins of unknown function

tsaMBCD $D_{1}$ and $t s a M B C D_{2}$, but within the transposon $(\mathrm{Tn} t s a)$, are two identical open reading frames (ORFs) which were designated $t s a Q_{1}$ and $t s a Q_{2}$ (Tralau et al. 2001) and which could encode an IclR-type regulator.

Molecular and physiological data are now presented which show that TsaR also binds to the promoter region of tsaT and that both copies of $t s a Q$ function as additional regulator(s) for the $t s a$ locus, specifically for $t s a T$. Thus, the whole $t s a$ system, including $t s a M B C D_{1}, t s a T$, tsaR and $t s a Q_{1,2}$, can be considered as a common functional regulatory unit, R1 (Adhya 1999), which is controlled by at least two regulators.

\section{Materials and methods}

Bacteria, growth conditions, mutants and clones

Comamonas testosteroni T-2 (DSM 6577), C. testosteroni TER-1 and three metabolically different groups of TSA-degrading bacteria (Fig. 2; Schläfli Oppenberg et al. 1995; Tralau et al. 2001) were grown in minimal medium as described by Thurnheer et al. (1986). The $t$ saQ-mutants $\mathrm{TE}_{7}, \mathrm{TE}_{11}$ and $\mathrm{TE}_{7 \mathrm{C}}$ (Table 2) were grown in $6 \mathrm{mM}$ terephthalate (TER)-minimal salts medium with $30 \mu \mathrm{g}$ tetracycline $/ \mathrm{ml}\left(\mathrm{TE}_{7}, \mathrm{TE}_{11}\right)$ or $30 \mu \mathrm{g}$ tetracycline $/ \mathrm{ml}$ and $110 \mu \mathrm{g}$ chlo- ramphenicol/ml $\left(\mathrm{TE}_{7 \mathrm{C}}\right)$. Growth was estimated by turbidity measurements (optical density at $580 \mathrm{~nm}$ ) and converted to protein using a correlation curve (Tralau et al. 2001).

Escherichia coli M10, generated to over-express TsaR with a C-terminal, 6-fold His-tag (TsaR $\left.{ }^{\text {His }}\right)$, was grown in Luria-Bertani medium (Tralau et al. 2003). E. coli DH5 $\alpha$ [pJB866], as donor for the broad-host-range vector pJB866 (GenBank accession number U8200), was kindly provided by J.M. Blatny and grown according to Blatny et al. (1997). E. coli JM109, as a donor of pMP141.1 $\left(\mathrm{Cm}^{\mathrm{r}}\right.$, chloramphenicol resistance cassette), was a gift from M. Providenti (Providenti et al. 2001).

\section{PCR, RT-PCR, quantification of DNA and cycle-sequencing}

PCR was done as described by Tralau et al. (2003). Cells for the preparation of RNA were pre-grown in TSA-salts medium before transfer to the required selective medium and were then harvested before the mid-log phase $(\leq 180 \mu \mathrm{g}$ protein $/ \mathrm{ml})$. Total RNA from

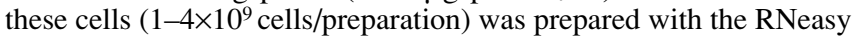
mini kit and the RNase-free DNase set (Qiagen, Hilden, Germany), following the protocol of the manufacturer. The First strand cDNA synthesis kit (MBI Fermentas) was used for reverse transcription of RNA $(0.5 \mu \mathrm{g})$. RNA was quantified photometrically (absorbance at $260 \mathrm{~nm}$ ) and DNA was quantified fluorimetrically (DyNA Quant 200; Hoefer), according to the manufacturer's instructions.

The following primers were used for RT-PCR (Table 1). TsaOp 11 and TsaReg 4 were used for the reverse transcription of mRNA for $t s a R$ and for amplification of cDNA, TsaOp 12 and TsaPrim 1 were used for the reverse transcription of mRNA for tsaMB and for amplification of cDNA, PsTs-11 and TsaTrf were used for the reverse transcription of mRNA for $t s a Q$ and for amplification of cDNA and TT-orf- 1 and TT-orf- 2 were used for the reverse transcription of mRNA for tsaT and for amplification of cDNA. Primers for PCR detection of $t s a Q$ in enrichment cultures (Fig. 2) were TsaQ-a and TsaQ-b. Fragments used for band-shift assays within the $t s a T$ promoter region were amplified with the following primer pairs (Table 1): tsaTC1 and tsaTC2 (fragment C), tsaTD1 and tsaTC2 (fragment D), tsaTE1 and tsaTC1 (fragment E) and tsaTF1 and tsaTC2 (fragment F). Fragments A and B (Table 3) were amplified as described by Tralau et al. (2003).

DNA was sequenced as described by Tralau et al. (2003). Sequence data were analyzed using standard software (Edit View from 
Table 1 PCR primers, their sequence and function. Relevant restriction sites are in italics

\begin{tabular}{|c|c|}
\hline Primer name & Sequence \\
\hline \multicolumn{2}{|l|}{ RT-PCR } \\
\hline TsaOp 11 & 5'-CCG GCG CAG CAC GTA AAT GGT-3' \\
\hline TsaReg 4 & 5'-GGC GCT GGG AGG GGC ACA TCA-3' \\
\hline TsaOp 12 & 5'-TGG GCA GGG CGA GGT CAA TGT-3' \\
\hline TsaPrim 1 & 5'-CGT GGT GGC GCT GGA AAA C-3' \\
\hline PsTs-11 & 5'-GCG CGT GCC CAT GGT CAC GGT CAG-3' \\
\hline TsaTrf & 5'-GGG GCT CGA AAT CCT GTC TTG TT-3' \\
\hline TT-orf-1 & 5'-GGC CCG GGG CGG CCG CAC ACT AGT GGC TTA GCG GTT GGC GGC GGC C-3' \\
\hline TT-orf-2 & 5'-GGA GAC AAA CAT GGA TTT CCG CCG CCG CC-3' \\
\hline \multicolumn{2}{|l|}{ PCR and cloning } \\
\hline TsaQ-a & 5'-GCG CGT GTT TTC ACG GGG CGC TGG TGT CGC-3' \\
\hline TsaQ-b & 5'-CAG CCC AAG CAA CTG GTG CTG CTG CCG GGC GA-3' \\
\hline pJB866-Tet1EcoRI & 5'-CAT CGC GGA ATT CGA GCA GCG CCT GCC TGA A-3' \\
\hline pJB866-Tet2HindIII & 5'-GGG CCG AGC GCA GAA GCT TTC CTG CAA CTT TAT CC-3' \\
\hline TsaQ-12HindIII & 5'-GTT CCT GGT GGG $A A G C T T$ CGA TGC GGT TGC GCG-3' \\
\hline TsaQ-21EcoRI & 5'-CGC GCA ACC GCG AAT TCC GTG CCC ACC AGG AAC-3' \\
\hline CmapMP141.1r & 5'-CGG GCC TCT TCG CTA TTA C-3' \\
\hline CmapMP141.11 & 5'-GGC ACC CCA GGC TTT ACA CTT TAT-3' \\
\hline TsaQ-12EcoRI & 5'-GTT CCT GGT GGG GAA TTC CGA TGC GGT TGC GCG-3' \\
\hline IS772u & 5'-TTG GCT ATG GGC TGC ACC GGC GAA ACA CTC A-3' \\
\hline IS772 1 & 5'-TGA GTG TTT CGC CGG TGC AGC CCA TAG CCA A-3' \\
\hline TnTet-1 & 5'-CGC CTG TTT CGG GTT CGG GAT GGT-3' \\
\hline PsTs-9 & 5'-CGC GCC GCT CAG AAC TCT TTG G-3' \\
\hline $\mathrm{Cm} 3$ & 5'-AAG ATC CGA AGG TCA TTG AGC AG-3' \\
\hline \multicolumn{2}{|c|}{ Generation of fragments used in band-shift assays } \\
\hline tsaTC1 & 5'-GCC CTG CCC ATC GCC TTC A-3' \\
\hline tsaTC2 & 5'-ATC TTG GTC ATG GGG TTC TGC-3' \\
\hline tsaTD1 & 5'-CGA TAA CAC TGG AGA CAA ACA TG-3' \\
\hline tsaTE1 & 5'-GTG TTA TCG AGG CCG CTG GGC ATG-3' \\
\hline tsaTF1 & 5'-CCT TTG CAC CGC CGC CCT GAT CG-3' \\
\hline tsaM-C & 5'-AAA AAT CTT GAG CCA GGT-3' \\
\hline tsaB-N & 5'-TTG AGC TTT TCG TGA ATC-3' \\
\hline Psz-Prom 1 & 5'-GGT CGG GGC AGA GCG GAT GTC-3' \\
\hline Psz-Prom2 & 5'-CGG TTG CCA AAA GTG TCG GAA GAG-3' \\
\hline
\end{tabular}

Perkin Elmer, with the GCG program package, and the DNAstar package from Lasergene) and the Internet-based Neural network promoter prediction tool (NNPP, http://searchlauncher.bcm.tmc.edu/ seq-search/gene-search.html; Reese et al. 1996).

The DNA size markers used were $\lambda$-DNA cut with $E c o$ RI and HindIII (NewEngland BioLabs) and a 1-kb ladder (MBI Fermentas) with a range from $0.25 \mathrm{~kb}$ to $10 \mathrm{~kb}$.

\section{Knock-out mutagenesis}

Knock-out of $t s a Q$ was done by homologous recombination of the original gene locus with a linear PCR product of $t s a Q$ with either an inserted tetracycline-resistance gene $\left(\mathrm{Tet}^{\mathrm{r}}\right)$ or a $\mathrm{Cm}^{\mathrm{r}}$ cassette. The appropriate inserts were constructed as follows. Tet $^{r}$ from pJB866 was amplified with primers pJB866-Tet1EcoRI and pJB866-Tet2HindIII, thus introducing primer-encoded restriction sites for both EcoRI and HindIII. The first two-thirds of gene $t s a Q$ (positions 39-738 in GenBank sequence AY227144) were amplified with primers TsaQ-a and TsaQ12HindIII and the last third (positions 742-1,146 in sequence AY227144) with primers TsaQ-b and TsaQ-21EcoRI. This introduced a restriction site for either HindIII or EcoRI. The resulting PCR products were digested with EcoRI and HindIII and ligated with the amplified Tet $^{\mathrm{r}}$, which had been pre-digested with the same restriction enzymes. The ligation prod- uct was amplified with TsaQ-a and TsaQ-b. This resulted in a 2,811-bp Tet ${ }^{\mathrm{r}}-t s a Q$ knock-out construct, where Tet $^{\mathrm{r}}$ was inserted in reverse orientation between bases 572 and 573 of $t s a Q$. A knockout construct of $t s a Q$ with an inserted $\mathrm{Cm}^{\mathrm{r}}$ gene was similarly generated. Primers CmapMP141.1r and CmapMP141.11 were used to amplify the $\mathrm{Cm}^{\mathrm{r}}$ gene from pMP141.1 (Providenti et al. 2001). With the two primer pairs, TsaQ-a+TsaQ-12EcoRI and TsaQ$21 \mathrm{EcoRI}+\mathrm{TsaQ}-\mathrm{b}, t s a Q$ was again amplified in two segments. The three PCR products were digested with EcoRI, ligated and the resulting $\mathrm{Cm}^{\mathrm{r}}$-tsaQ-knock-out construct $\left(4,247 \mathrm{bp}\right.$, with $\mathrm{Cm}^{\mathrm{r}}$ in reverse orientation to $t s a Q$ between bp 572 and 573 , as confirmed by sequencing) was amplified with TsaQ-a and TsaQ-b. Religation of $t s a Q$ without insert was avoided by dephosphorylation of the $t s a Q$ fragments prior to ligation. In both knock-out constructs, palindromic stem-loop-stem structures at the end of the resistance cassette (tet $t^{r}$ gene) or within the inserted sequence $\left(\mathrm{cm}^{r}\right.$ cassette), in addition to termination sequences $14 \mathrm{bp} 3^{\prime}$ to the $t s a D$ genes (Junker et al. 1997) should prevent transcription of anti-sense mRNA from the tsaMBCD operons.

PCR-amplified knock-out constructs were introduced into target cells by electroporation as described by Tralau et al. (2003). The knock-out mutants of $C$. testosteroni $\mathrm{T}-2$, which were generated during this work, are listed in Table 2. The knock-out was tested by PCR with primer pairs TsaQ-a and IS772u for $t s a Q_{2}$ and primer pairs TsaQ-a and IS7721 for $t s a Q_{1}$; and the lengths of the 


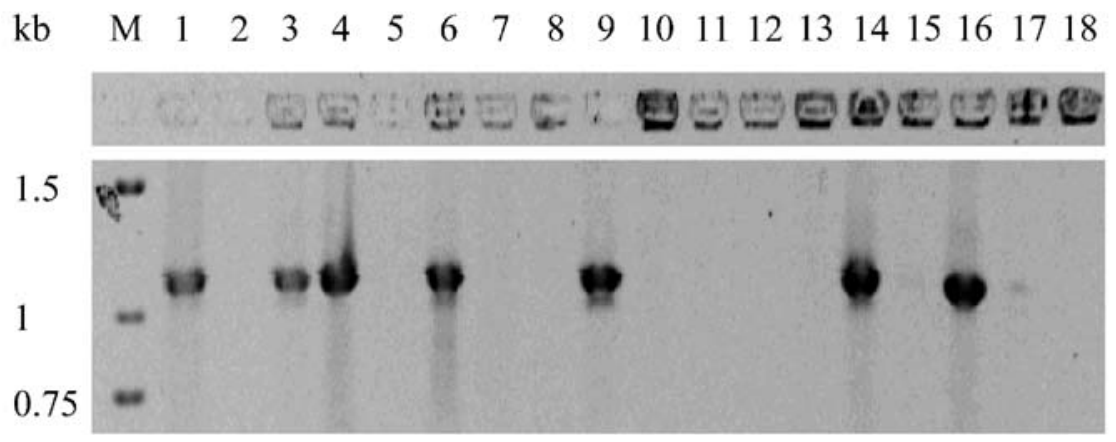

Fig. 2 Detection of $t s a Q$ by PCR. Our collection of 17 cultures able to utilize TSA and a derivative of strain T-2 lacking the pTSA plasmid were examined by PCR, using primers TsaQ-a and TsaQ-b and an expected PCR product length of $1,108 \mathrm{bp}$. Cultures containing the tsa operon are indicated in bold. Lane 1 C. testosteroni T-2 (positive control), lane 2 C. testosteroni TER-1 (negative control), lane 3 Delftia acidovoransMu4, lane 4 Stenotrophomonas maltophiliaMuF, lane 5 mixed culture KNP1, lane 6 Delftia acidovorans MoP1, lane 7 Hydrogenophaga teniospiralis EWM1, lane 8 C. testosteroni EW13, lane 9 Pseudomonas pseudoalcaligenes EWL2, lane 10 Acidovorax delafieldii TKA, lane 11 S. maltophilia VLB, lane 12 mixed culture VLB1, lane 13 S. maltophilia RLB, lane 14 Burkholderia pickettii TKR, lane 15 unidentified isolate TA12, lane 16 Pseudomonas sp. ISP2, lane 17 mixed culture SCM, lane 18 C. testosteroni OrL1, lane M 1-kb marker

predicted PCR products were $4.8 \mathrm{~kb}$ ( Tet $^{\mathrm{r}}, 3.1 \mathrm{~kb}$ for wild type) and $8.1 \mathrm{~kb}\left(\mathrm{Cm}^{\mathrm{r}}, 4.7 \mathrm{~kb}\right.$ for wild type), respectively. PCRs with primers TnTet-1 and PsTs-9 were done to localize Tet $^{\mathrm{r}}$ and with primers $\mathrm{Cm} 3$ and PsTs-9 to localize $\mathrm{Cm}^{\mathrm{r}}$ in $t s a Q$. The insertion sites were confirmed by sequencing.

Protein purification and quantification, gel electrophoresis, preparation of His-tagged protein and band-shift assays

His-tagged regulator protein ( $\mathrm{TsaR}^{\mathrm{His}}$ ) was expressed heterologously in E c coli and isolated as described by Tralau et al. (2003). Soluble protein was quantified colorimetrically (Bradford 1976) and the purity of protein fractions was examined by SDS-PAGE (Schägger and von Jagow 1987). Protein was stained with either soluble (Sambrook et al. 1989) or colloidal (Neuhoff et al. 1988) Coomassie brilliant blue and compared with protein standards given by Tralau et al. (2003). Gel retardation assays to quantify the binding of $\mathrm{TsaR}^{\text {His }}$ to DNA (using $2 \mu \mathrm{g}$ of protein for band-shifts) or to determine the values of the dissociation constant $\left(K_{\mathrm{D}}\right.$; using $0.3-1.5 \mu \mathrm{g}$ of protein) were as described by Tralau et al. (2003).

Nucleotide sequence accession numbers

The putative promoter region with the partial gene sequence of tsaT is available in the NCBI GenBank library under accession number AY044256; and the Tntsa sections covering $t s a Q_{1}$ and $t s a Q_{2}$ are available under accession numbers AY227144 and AY227145, respectively.

\section{Results and discussion}

$t s a Q$ is part of the $t s a$ transposon

The $t s a$ operon is widespread (Tralau et al. 2001), but the general composition of Tntsa (Fig. 1) has not been estab- lished. We have now examined our TSA-utilizing cultures (Fig. 2) to discover which ones contain the $t s a Q$ gene(s). The clear positive and negative controls using the PCR primer pair TsaQ-a and TsaQ-b (Fig. 2, lanes 1, 2) allow us to state that those cultures which lacked the $t s a$ operon also lacked the $t s a Q$ gene (Fig. 2, lanes 5, 7, 8, 10-13, 17, 18). Of the seven $t s a^{+}$cultures (apart from strain T-2), six contained tsaQ (Fig. 3, lanes 3, 4, 6, 9, 14, 16) and one, strain TA12, did not (Fig. 3, lane 15). This observation coincides with the distribution of the complete tsa transposon, which lacks tsaT in TA12 (Mampel 2000; Tralau et al. 2001). The $t s a Q$ gene is thus, presumably, a common component of $t s a$ transposons. Strain TA12 obviously has a different overall strategy, especially concerning regulation and transport, to degrade TSA via TsaMBCD .

The transcription of $t s a Q$ in C. testosteroni T- 2 under a range of growth conditions was examined by RT-PCR (Fig. 3). The positive and negative controls allowed us to conclude that at least one of the two tsaQ genes was transcribed when TSA, TCA, $p$-sulfobenzoate (PSB) or TER was utilized, but not when the ring-cleavage substrate protocatechuate (PCA) was the sole carbon source. This induction pattern differs from the results obtained for the transcription of $t s a R$ and $t s a M B C D$ (Table at the foot of Fig. 3). The latter genes were transcribed in the presence of TSA, TCA and PSB but not with TER. The transcription of $t s a Q$ during the growth of strain T-2 with TER is presumably largely irrelevant to the present work, because strain TER-1 grows normally with TER. Strain TER-1 is a mutant of strain T-2 which has lost pTSA. Further, the complete or partial loss of TsaQ in strain T-2 was without effect on growth with TER (see below). However, the data do show that the regulation of $t s a Q$ is different from that of $t s a R$ and $t s a M B C D$.

\section{The sequence of $t s a Q$ and another ORF}

The $t s a Q$ gene comprised $837 \mathrm{bp}$, and the deduced amino acid sequence (278 amino acids) was analyzed (NCBI BLAST; Altschul et al. 1997). No enzymic function could be attributed to the sequence. The most similar protein (NC_00431.11,33\% identity) was found in the genome of Brucella suis 1330 . It encodes a protein (284 amino acids) which is annotated as a transcriptional regulator of the IclR family. PcaR (AAC38247) from Rhodococcus opacus, a proven IclR-type regulator (Eulberg and Schloemann 1998; 


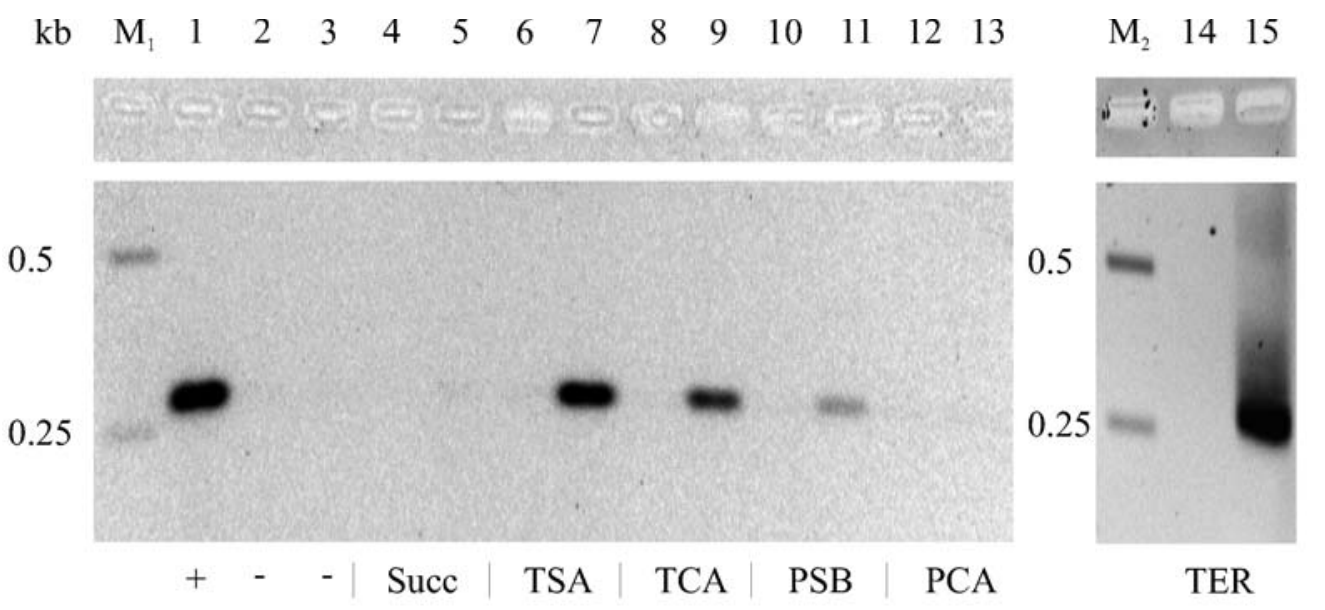

\begin{tabular}{ccccccc}
\hline \multirow{2}{*}{ Gene } & \multicolumn{7}{c}{ Growth substrate } \\
\cline { 2 - 7 } & succinate & TSA & TCA & PSB & PCA & TER \\
\hline$t$ saR & - & + & + & + & - & - \\
$t$ saMBCD & - & + & + & + & - & - \\
tsaQ & - & + & + & + & - & + \\
\hline
\end{tabular}

Fig. 3 Detection by RT-PCR of transcripts of $t s a Q$ in cells of C. testosteroni T-2 grown with different substrates, with tabulation of detection of transcripts of $t s a Q$, tsaR and tsaMBCD. Lanes $M_{1}$, $M_{2}$ DNA markers with sizes indicated in kilobases, lane 1 PCR with total DNA from C. testosteroni T-2 (positive control), lane 2 PCR with water as template (negative control), lane 3 RT-PCR with water as template (negative control), lane 4 PCR with total RNA from succinate-grown cells, lane 5 RT-PCR with total RNA from succinate-grown cells, lane 6 PCR with total RNA from TSAgrown cells, lane 7 RT-PCR with total RNA from TSA-grown cells, lane 8 PCR with total RNA from TCA-grown cells, lane 9 RT-PCR with total RNA from TCA-grown cells, lane 10 PCR with total RNA from PSB-grown cells, lane 11 RT-PCR with total RNA from PSB-grown cells, lane 12 PCR with total RNA from PCAgrown cells, lane 13 RT-PCR with total RNA from PCA-grown cells, lane 14 PCR with total RNA from TER-grown cells, lane 15 RT-PCR with total RNA from TER-grown cells. Symbols in Table: + transcription, - no transcription

Eulberg et al. 1998), shares 25\% identity with TsaQ. A helix-turn-helix motif for DNA-binding could be located over amino acids 19-107, based on a search for conserved domains (Altschul et al. 1997). The amino acid sequence over positions 77-260 showed similarities to the consensus sequence for IclR-type regulators (Altschul et al. 1997), so we hypothesize that TsaQ has a regulatory function.
The left and right ends of Tntsa were believed to contain no ORFs (Tralau et al. 2001). Renewed analysis revealed the presence of ORFs of identical length (807 bp) and high sequence identity (98.5\%; Fig. 1), in the opposite orientation to the $t s a Q$ genes. Their function is unknown, but some similarity to esterases allows the hypothesis that a TCA ester might be the substrate, if a gene is expressed.

\section{The phenotype of $t s a Q$ mutants}

Two mutants with a single disruption in a $t s a Q$ gene and a double mutant were generated. Growth of $C$. testosteroni T-2 with succinate, PCA or TER as substrate was not affected by elimination of either a single copy of the $t s a Q$ gene, or both $t s a Q$ genes (Table 2). When only $t s a Q_{1}$ was inactivated, growth of mutant $\mathrm{TE}_{7}$ with TSA was prevented, whereas full growth with TCA or PSB was attained, but very slowly. Loss of $t s a Q_{2}$ (mutant $\mathrm{TE}_{11}$ ) was less severe in its effect, full growth with TSA or TCA was very slow and growth with PSB was somewhat slower than strain T-2 (Table 2). When both copies of $t s a Q$ were inactivated, the mutant $\left(\mathrm{TE}_{7 \mathrm{C}}\right)$ was unable to grow with TSA but showed normal growth with TCA, while growth with
Table 2 Growth of Comamonas testosteroni $\mathrm{T}-2$ and of tsa $Q_{1^{-}}$and $t s a Q_{2}$-mutants with different substrates (see Materials and methods). Growth media were inoculated with a 1:50 dilution of exponentially growing cells. $N G$ No growth

\begin{tabular}{|c|c|c|c|c|c|c|c|}
\hline \multicolumn{2}{|c|}{ Organism } & \multicolumn{6}{|c|}{ Substrate (days to full growth) } \\
\hline Strain & Genotype & Succinate & TSA & TCA & PSB & TER & PCA \\
\hline $\mathrm{T}-2$ & $t s a Q_{1}^{+} t s a Q_{2}^{+}$ & 1.5 & 1.5 & 1.5 & 1.5 & 1.5 & 1.5 \\
\hline $\mathrm{TE}_{7}$ & $t s a Q_{1}$, tet $^{r}$ & 1.5 & NG & 12.0 & 12.0 & 1.5 & 1.5 \\
\hline $\mathrm{TE}_{11}$ & $t s a Q_{2}$, tet $^{r}$ & 1.5 & 12.0 & 12.0 & 3.0 & 1.5 & 1.5 \\
\hline $\mathrm{TE}_{7 \mathrm{C}}$ & $t s a Q_{1} t s a Q_{2}$, tet $^{r}, \mathrm{~cm}^{r}$ & 1.5 & NG & 1.5 & 1.0 & 1.5 & 1.5 \\
\hline
\end{tabular}


PSB was slightly faster than growth of the parent organism (Table 2). Both copies of the $t s a Q$ gene are identical, so we have no explanation for the different growth patterns of strains $\mathrm{TE}_{7}$ and $\mathrm{TE}_{11}$.

Normal growth of the double mutant with TCA indicates that the regulator TsaR and the degradative enzymes $($ TsaMBCD 1$)$ are fully functional. The differences between the two single mutants (Table 2) imply that more $\mathrm{TsaQ}_{1}$ was expressed than $\mathrm{TsaQ}_{2}$. The faster growth with PSB (Table 2) possibly indicates some regulatory interaction of TsaQ with the IclR-type binding site for PSB regulation: cross-binding of distinct but evolutionarily related regulators to each others' promoters has been observed with some LysR-type regulators (van der Meer et al. 1991; von Lintig et al. 1994; McFall et al. 1997).

The effects in the double mutant, in particular growth with TCA, argue against a direct interaction of TsaQ with tsaR or tsaMBCD $D_{1}$ at the common promoter region between the $t s a R$ and $t s a M$ genes (Fig. 1; see Tralau et al. 2003). We thus looked for gene(s) independent of the metabolism of TCA, but essential for the degradation of TSA, that could be a target for regulatory $\mathrm{TsaQ}(\mathrm{s})$. The only serious candidate is a gene attributed to the transport of TSA (Mampel 2000), tsaT, which lies downstream of tsaR (Fig. 1; Tralau et al. 2001). Another transport component, TsaS (Fig. 1), is expressed constitutively (Mampel and Cook, unpublished).

Transcription of tsaT in C. testosteroni T-2 with different growth substrates was examined by RT-PCR (data not shown). TSA-grown cells of strain T-2 showed transcription of $t s a T$, but no mRNA for $t s a T$ could be detected in cells grown with succinate, PCA, PSB, TER or TCA. These results link $t s a T$ exclusively with the degradation of TSA. Similarly, $t s a Q$ regulates a function exclusive to the degradation of TSA. So we presumed that TsaQ plays a regulatory role in the expression, or function, of $t s a T$. Whether this is a direct interaction between TsaQ and the transporter TsaT, as was found for MalT binding to the ABC transporter subunit MalY (Böhm et al. 2002; Schlegel et al. 2002), or an interference with the binding of the other regulator (TsaR; see next section) to the promoter of $t s a T$ will be the subject of future studies.

The regulator of the $t s a$ operon (TsaR)

binds to the promoter region of $t s a T$

The putative promoter region of $t s a T, 400 \mathrm{bp}$ between tsaS and extending into tsaT (GenBank accession number AY044256; Fig. 5) was examined for interactions with TsaR in band-shift assays. Control experiments with $\mathrm{TsaR}^{\mathrm{His}}$ and a coding region in the $t s a$ transposon (Table 3, fragment A; Fig. 4) and with a promoter region independent of Tntsa (Table 3, fragment B; data not shown) showed no interaction. In contrast, DNA from the promoter region of $t s a T$ migrated a shorter distance in the presence of $\mathrm{TsaR}^{\mathrm{His}}$; and larger amounts of $\mathrm{TsaR}^{\mathrm{His}}$ caused reduced mobility for larger amounts of DNA, independent of the presence of TSA (data not shown) or its absence (Fig. 4). There is, thus,

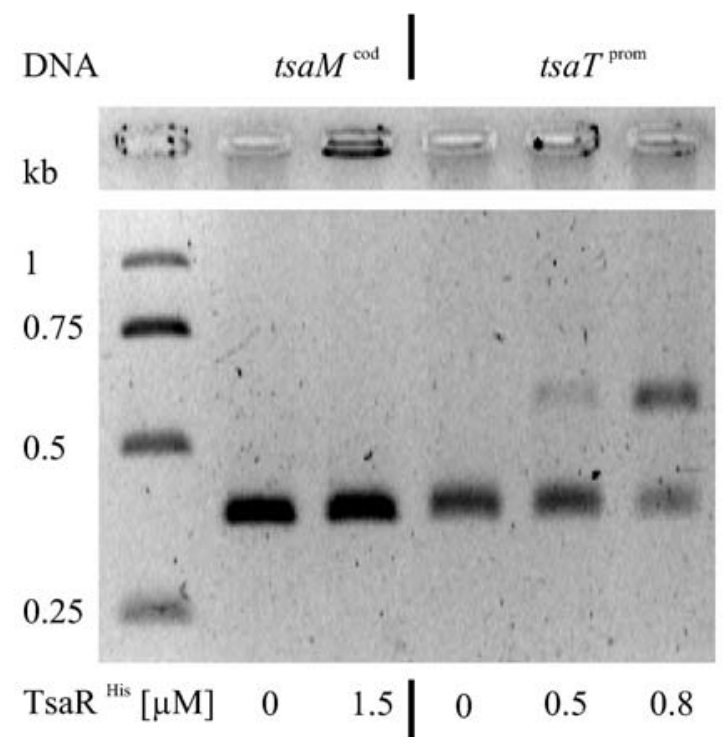

Fig. 4 Effect of TsaR ${ }^{\text {His }}$ on the mobility of different fragments of DNA from the $t s a$ transposon in the absence of TSA. Lane 1 1-kb marker, lane 2 coding region of $t s a M B$ in the absence of $\mathrm{TsaR}^{\mathrm{His}}$ (negative control), lane 3 coding region of $t s a M B$ in the presence of $1.5 \mu \mathrm{M} \mathrm{TsaR}{ }^{\text {His }}$ (negative control), lane 4 promoter region of $t s a T$ in the absence of $\mathrm{TsaR}^{\mathrm{His}}$, lane 5 promoter region of tsaT in the presence of $0.5 \mu \mathrm{M} \mathrm{TsaR}^{\mathrm{His}}$, lane 6 promoter region of $t s a T$ in the presence of $0.8 \mu \mathrm{M}$ TsaR ${ }^{\text {His }}$

a specific interaction of $\mathrm{TsaR}^{\mathrm{His}}$ with the promoter region of $t s a T$, so transcription of the latter is presumably under the control of both TsaR and TsaQ.

The $K_{\mathrm{D}}$ of $\mathrm{TsaR}^{\text {His }}$ for the whole promoter region of tsaT (Fig. 5, fragment C) was determined in the absence of TSA $\left(K_{\mathrm{D}}=0.9 \mu \mathrm{M}\right)$ and in its presence $\left(K_{\mathrm{D}}=1.3 \mu \mathrm{M}\right.$ at $0.1 \mathrm{mM}$ TSA, $1.2 \mu \mathrm{M}$ at $1 \mathrm{mM}$ TSA, $0.8 \mu \mathrm{M}$ at $6 \mathrm{mM}$ TSA). These values are very similar to those observed for the promoter region between $t s a R$ and $t s a M$ (Tralau et al. 2003).

The DNA sequence upstream of $t s a T$ was analyzed in order to find consensus sequences for $\sigma^{70}$-dependent promoters and possible binding sites for LysR-type regulatory proteins (Schell 1993). A putative Pribnow box was found at positions 238-245. The corresponding putative recognition site for the RNA polymerase was located at positions 214-219. The transcriptional start-site could be predicted by NNPP at position 249 and a consensus for a Shine-Dalgarno sequence could be found at positions 266-270 (Fig. 5). However, a consensus motif (T-N $\mathrm{N}_{11}-\mathrm{A}$; see Schell 1993) for the binding of LysR-type regulators was not detected.

There are several binding sites for TsaR in the promoter region between $t s a R$ and $t s a M$ (Tralau et al. 2003), so we probed for multiple binding sites in the complete promoter region of $t s a T$. The whole promoter, fragment $\mathrm{C}$ (Fig. 5; Table 3), gave a single band-shift with $\mathrm{TsaR}^{\mathrm{His}}$ both in the presence and absence of TSA. Band-shift assays were then done with overlapping subfragments of the promoter region. This showed that there was no binding site in the coding region of fragment $\mathrm{C}$ (Table 3 , fragment $\mathrm{F}$; 
gccetgcccatcgccttcatgggcgtggtgctgggcaaccgcctggeccggcacataccgcecccggccatgcgccgcgccatggccgtgttgctg

100

150

atcgccagcggcctgtcgctcacccagcacctctggcggtgaacceggcggggcactggcgcccagcctagggttaacgcttatctgcgtttccga

200

250

287

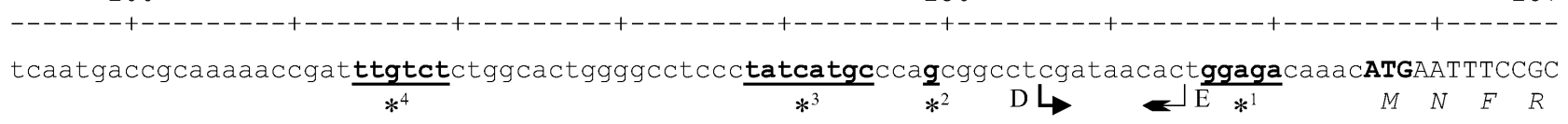
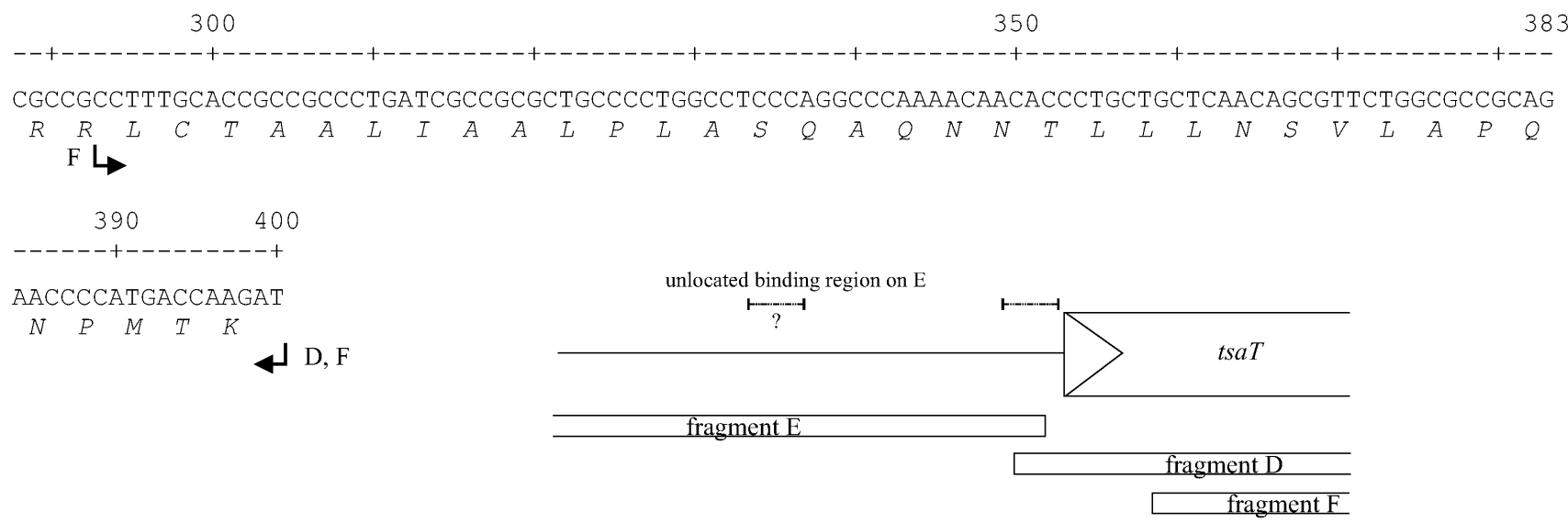

Fig. 5 Sequence of PCR-fragment C (GenBank accession number AY044256) and structure of the promoter of $t s a T$. Fragment $\mathrm{C}$ (Table 3) extends over the putative promoter region of tsaT into the coding region of the gene. Gene tsaT is shown in uppercase, the start codon is shown in bold. The putative ribosomal binding site $(* 1)$, transcriptional start $(* 2)$, Pribnow box $(* 3)$ and -35 region $(* 4)$ are shown in bold and underlined. Primers for fragment D are marked in bold, with long arrowheads; and those for fragment $\mathrm{E}$ and $\mathrm{F}$ are marked in bold, with short arrowheads (see also Table 3 ). Putative binding regions for $\mathrm{TsaR}^{\mathrm{His}}$ are indicated in the sketch of fragments D, E and F (below main sequence)

Fig. 5) and one binding region could be detected upstream of the coding region, indicated by a weak shift $(17 \%)$ of fragment D (Table 3; Fig. 5). Fragment E showed two shifted bands (Table 3). This indicates that at least two binding sites are located on this fragment, one in the region overlapping fragment D (nucleotides 250-267) that probably mediates the weak shift of fragment $\mathrm{D}$ and another which could not be specified (Table 3; Fig. 5). The binding of $\mathrm{TsaR}^{\mathrm{His}}$ to these sites was independent of the presence of TSA. This allows the conclusion that TsaR cannot be the only regulator for $t s a T$, because the inducing substrate TSA does not mediate any change in the occupational state of the binding regions for $\mathrm{TsaR}^{\mathrm{His}}$. This contrasts with our finding for the promoter of $t s a M B C D_{1}$, where TSA-dependent and TSA-independent binding was observed (Tralau et al. 2003). We presume that the second regulator, TsaQ, mediates a regulatory separation of the enzymes required for the transformation of TSA to PSB (tsaMBCD; Junker et al. 1997) and the transport for TSA (probably tsaT; Locher et al. 1993; Mampel 2000). This enables $C$. testosteroni $\mathrm{T}-2$ to use the same set of enzymes
Table 3 Results for the DNAbinding assays with $\mathrm{TsaR}^{\mathrm{His}}$ and PCR products of the promoter region of tsaT (cf. Fig. 5). Values in parentheses are the percentages of band-shifted DNA; and, if there are two bands, the first value is for the smaller shift. A coding region of $t$ saMB (fragment A) and the promotor region of pszA (fragment $B$ ) were used as negative controls

\begin{tabular}{llll}
\hline Fragment & Location of fragment & \multicolumn{2}{l}{ Band shift(s) } \\
\cline { 3 - 4 } & & no TSA & 6 mM TSA \\
\hline A & $\begin{array}{l}2,397-2,782 \text { in U32622; } \\
\text { coding region in } t \text { saMB }\end{array}$ & None & None \\
B & $\begin{array}{l}\text { Promoter region of } p s z A, \text { AY044257 } \\
\text { C-400; promoter region of } t \text { saT }\end{array}$ & None & None \\
and 5' region of $t$ tsaT, AY044256 & $1(100 \%)$ & $1(100 \%)$ \\
D & $256-400$, AY044256 & $1(17 \%)$ & $1(17 \%)$ \\
E & $1-264$, AY044256 & $2(69 \%, 31 \%)$ & $2(67 \%, 33 \%)$ \\
F & $293-400$, AY044256 & None & None \\
\hline
\end{tabular}


very efficiently for the degradation of several substrates as, e.g. TCA. The location of $t s a R$ and $t s a Q$ within Tntsa ensures that the transfer of this part of the degradative pathway (Fig. 1; Junker and Cook 1997; Tralau et al. 2001) is accompanied by the transfer of the complete regulatory system.

We conclude that not only tsaR and tsaMBCD but also $t s a Q$ and $t s a T$ are part of one common regulatory unit, regulon $\mathrm{R} 1$, leaving open the question why $t s a Q$ is transcribed when TCA or TER are growth substrates, although growth with these substrates is not prevented when $t s a Q$ is knocked-out.

Acknowledgements We are grateful to W. Boos for helpful discussions. T.T. was funded by the Deutsche Forschungsgemeinschaft (to A.M.C., J.R.), the European Union (SUITE: ENV4-CT980723; to A.M.C.), the University of Konstanz and the Fonds der Chemischen Industrie.

\section{References}

Adhya S (1999) Regulation of gene expression: operons and regulons. In: Lengeler JW, Drews G, Schlegel HG (eds) Biology of the prokaryotes. Thieme, Stuttgart, pp 437-468

Altschul SF, Madden TL, Schäffer AA, Zhang J, Zhang Z, Miller W, Lipman DJ (1997) Gapped BLAST and PSI-BLAST: a new generation of protein database search programs. Nucleic Acids Res 25:3389-3402

Blatny JM, Brautaset T, Winther Larsen HC, Karunakaran P, Valla S (1997) Improved broad-host-range RK2 vectors useful for high and low regulated gene expression levels in gram-negative bacteria. Plasmid 38:35-51

Böhm A, Diez J, Diederichs K, Welte W, Boos W (2002) Structural model of MalK, the ABC subunit of the maltose transporter of Escherichia coli: implications for mal gene regulation, inducer exclusion, and subunit assembly. J Biol Chem 277:3708-3717

Bradford M (1976) A rapid and sensitive method for the quantitation of microgram quantities of protein utilizing the principle of protein-dye binding. Anal Biochem 72:248-254

Cook AM, Laue H, Junker F (1999) Microbial desulfonation. FEMS Microbiol Rev 22:399-419

Eulberg D, Schloemann M (1998) The putative regulator of catechol catabolism in Rhodococcus opacus 1CP - an IclR-type, not a LysR-type transcriptional regulator. Antonie Van Leeuwenhoek 74:71-82

Eulberg D, Lakner S, Golovleva LA, Schlömann M (1998) Characterization of a protocatechuate catabolic gene cluster from Rhodococcus opacus 1CP: evidence for a merged enzyme with 4-carboxymuconolactone-decarboxylating and 3-oxoadipate enol-lactone-hydrolyzing activity. J Bacteriol 180:1072-1081

Junker F, Cook AM (1997) Conjugative plasmids and the degradation of arylsulfonates in Comamonas testosteroni. Appl Environ Microbiol 63:2403-2410

Junker F, Kiewitz R, Cook AM (1997) Characterization of the $p$-toluenesulfonate operon tsaMBCD and tsaR in Comamonas testosteroni T-2. J Bacteriol 179:919-927

Lintig J von, Kreusch D, Schroder J (1994) Opine-regulated promoters and LysR-type regulators in the nopaline (noc) and octopine (occ) catabolic regions of Ti plasmids of Agrobacterium tumefaciens. J Bacteriol 176:495-503

Locher HH, Leisinger T, Cook AM (1989) Degradation of $p$-toluenesulphonic acid via sidechain oxidation, desulphonation and meta ring cleavage in Pseudomonas (Comamonas) testosteroni T-2. J Gen Microbiol 135:1969-1978
Locher HH, Malli C, Hooper S, Vorherr T, Leisinger T, Cook AM (1991) Degradation of $p$-toluic acid ( $p$-toluenecarboxylic acid) and $p$-toluene sulphonic acid via oxygenation of the methyl sidechain is initiated by the same set of enzymes in Comamonas testosteroni T-2. J Gen Microbiol 137:2201-2208

Locher HH, Poolman B, Cook AM, Konings WN (1993) Uptake of 4-toluenesulfonate by Comamonas testosteroni T-2. J Bacteriol 175:1075-1080

Mampel J (2000) Transport- und Regulationsphänomene beim Abbau von 4-Toluolsulfonat in Comamonas testosteroni. PhD thesis, University of Konstanz, Konstanz

McFall SM, Parsek MR, Chakrabarty AM (1997) 2-Chloromuconate and ClcR-mediated activation of the $c l c A B D$ operon: in vitro transcriptional and DNase I footprint analyses. J Bacteriol 179:3655-3663

Meer JR van der, Frijters AC, Leveau JH, Eggen RI, Zehnder AJ, Vos WM de (1991) Characterization of the Pseudomonas sp. strain P51 gene $t c b R$, a LysR-type transcriptional activator of the $t c b C D E F$ chlorocatechol oxidative operon, and analysis of the regulatory region. J Bacteriol 173:3700-3708

Neuhoff V, Arold N, Taube D, Ehrhardt W (1988) Improved staining of proteins in polyacrylamide gels including isoelectric focusing gels with clear background at nanogram sensitivity using Coomassie brilliant blue G-250 and R-250. Electrophoresis 9:255-262

Providenti MA, Mampel J, MacSween S, Cook AM, Wyndham $\mathrm{RC}$ (2001) Comamonas testosteroni BR6020 possesses a single genetic locus for extradiol cleavage of protocatechuate. Microbiology 147:2157-2167

Reese MG, Harris NL, Eeckman FH (1996) Large scale sequencing specific neural networks for promoter and splice site recognition. In: Hunter L, Klein TE (eds) Biocomputing: proceedings of the 1996 Pacific symposium. World Scientific Publishing, Singapore

Riediker S, Ruckstuhl S, Suter MJ-F, Cook AM, Giger W (2000) $p$-Toluenesulfonate in landfill leachates: leachability from foundry sands and aerobic biodegradation. Environ Sci Technol $34: 2156-2161$

Sambrook J, Fritsch EF, Maniatis T (1989) Molecular cloning: a laboratory manual, 2nd edn. Cold Spring Harbor Laboratory Press, Cold Spring Harbor, N.Y.

Schägger H, Jagow G von (1987) Tricine-sodium dodecyl sulfatepolyacrylamide gel electrophoresis for the separation of proteins in the range from 1 to $100 \mathrm{kDa}$. Anal Biochem 166:368379

Schell MA (1993) Molecular biology of the LysR family of transcriptional regulators. Annu Rev Microbiol 47:597-626

Schläfli Oppenberg HR, Chen G, Leisinger T, Cook AM (1995) Regulation of the degradative pathways from 4-toluenesulphonate and 4-toluenecarboxylate to protocatechuate in $\mathrm{Co}$ mamonas testosteroni T-2. Microbiology 141:1891-1899

Schlegel A, Böhm A, Lee SJ, Peist R, Decker K, Boos W (2002) Network regulation of the Escherichia coli maltose system. J Mol Microbiol Biotechnol 4:301-307

Thurnheer T, Köhler T, Cook AM, Leisinger T (1986) Orthanilic acid and analogues as carbon sources for bacteria: growth physiology and enzymic desulphonation. J Gen Microbiol 132: 1215-1220

Tralau T, Cook AM, Ruff J (2001) Map of the IncP1 $\beta$ plasmid pTSA encoding the widespread genes $(t s a)$ for $p$-toluenesulfonate degradation in Comamonas testosteroni T-2. Appl Environ Microbiol 67:1508-1516

Tralau T, Mampel J, Cook AM, Ruff J (2003) Characterization of TsaR, an oxygen-sensitive LysR-type regulator for the degradation of $p$-toluenesulfonate in Comamonas testosteroni T-2. Appl Environ Microbiol 69:2298-2305 